\title{
LACTOBACILLUS DELBRUECKII SUBSP. BULGARICUS ZN541 VE STREPTOCOCCUS THERMOPHILUS Z1052 SUŞLARINDA BETA GALAKTOZİDAZ AKTIVİTESİ VE OPTİMİZASYON
}

\author{
Hazer Yüksekdağ ${ }^{1 *}$, Zehranur Yüksekdağ ${ }^{2}$ \\ ${ }^{1}$ Gazi Üniversitesi, Sağlık Hizmetleri Meslek Yüksekokulu, Gölbaşı Kampusu, Ankara, Türkiye \\ ${ }^{2}$ Gazi Üniversitesi, Fen Fakültesi, Biyoloji Bölümü, Biyoteknoloji ABD, Teknikokullar, Ankara, Türkiye \\ Geliş / Received: 30.03.2021; Kabul / Accepted: 06.09.2021; Online bask1 / Published online: 14.10.2021
}

Yüksekdă̆, H., Yüksekdăg, Z. (2021). Lactobacillus delbrueckii subsp. bulgaricus ZN541 ve Streptococcus thermophilus Z1052 suşlanında beta galaktozidaz aktivitesi ve optimizasyon. GIDA (2021) 46 (6) 13311342 doi: 10.15237 /gida.GD21059.

Yüksekdağ, H., Yüksekdă̆, Z. (2021). Beta galactosidase activity in Lactobacillus delbrueckii subsp. bulgaricus ZN541 and Streptococcus thermophilus Z1052 strains and optimization. GIDA (2021) 46 (6) 1331-1342 doi: 10.15237/gida.GD21059.

ÖZ

Çalışmada, 31 Lactobacillus delbrueckii subsp. bulgaricus ve 34 Streptococcus thermophilus bakteri kültürlerinde, onitrofenil-beta-D-galaktosit (o-NPG) substrat olarak kullanilarak, $\beta$-galaktosidaz enzim ve spesifik aktiviteleri taranmıştır. L. delbrueckii subsp. bulgaricus suşları 0.186-6.500 U/mg arasında spesifik aktivite gösterirken, $S$. thermophilus suşlar1 0.172-5.064 U/mg arasında spesifik aktivite göstermiştir. L. delbrueckii subsp. bulgaricus ZN541 (6.500 U/mg) ve $S$. thermophilus Z1052 (5.064 U/mg) suşlarının yüksek spesifik aktivite yeteneğine sahip oldukları tespit edilmiştir. Yüksek spesifik $\beta$-galaktozidaz aktivitesi gösteren ZN541 ve Z1052 suşlanı seçilerek, farklı koşulların ( $\mathrm{pH}$, sıcaklık, laktoz konsantrasyonu ve fermantasyon süresi) bu suşlara ait $\beta$ galaktozidaz enzimlerin aktivitelerine etkileri belirlenmiştir. ZN541 suşunda optimum enzim aktivitesi için gereken $\mathrm{pH}$ 'n 6.2 , sicaklığın $42^{\circ} \mathrm{C}$, laktoz konsantrasyonunun $\% 2$ ve fermantasyon süresinin 24 saat olduğu tespit edilmiştir. Z1052 suşunda ise optimum enzim aktivitesi için gereken $\mathrm{pH}$ 'ın 6.8 , sicaklı̆̆ı $42^{\circ} \mathrm{C}$, laktoz konsantrasyonun $\% 4$ ve fermantasyon süresinin 24 saat olduğu belirlenmiştir.

Anahtar kelimeler: $L$. delbrueckii subsp. bulgaricus, $S$. thermophilus, $\beta$-galaktosidaz, optimizasyon

\section{BETA GALACTOSIDASE ACTIVITY IN LACTOBACILLUS DELBRUECKII SUBSP. BULGARICUS ZN541 AND STREPTOCOCCUS THERMOPHILUS Z1052 STRAINS AND OPTIMIZATION}

\begin{abstract}
In this study, thirty-one Lactobacillus delbrueckii subsp. bulgaricus and thirty-four Streptococcus thermophilus were screened for $\beta$-galactosidase enzyme activities and specific activities. The $\beta$-galactosidase enzyme activities were determined by using o-nitrophenyl-beta-D-galactopyranoside (o-NPG) as a substrate. L. delbrueckii bulgaricus strains showed specific activity between 0.186-6.500 U/mg, while $S$. thermophilus strains exhibited specific activity between 0.172-5.064 U/mg. The highest specific enzyme activities among bacteria cultures were determined at L. delbrueckii subsp. bulgaricus ZN541 (6.500
\end{abstract}

\footnotetext{
* Yazışmalardan sorumlu yazar / Corresponding author

†: hazer@gazi.edu.tr, zehranur@gazi.edu.tr

(ग): (+90) 3124845635

且: (+90) 3124843649
}

Hazer Yüksekdağ; ORCID no: 0000-0001-7953-2920

Zehranur Yüksekdağ; ORCID no: 0000-0002-0381-5876 
$\mathrm{U} / \mathrm{mg}$ ) and S. thermophilus Z1052 (5.064 U/mg) strains. The ZN541 and Z1052 strains that showed high specific $\beta$-galactosidase activity were selected and the effects of different conditions $(\mathrm{pH}$, temperature, lactose concentration, and fermentation time) on the activities of $\beta$-galactosidase enzymes of these strains were determined. It was determined that the $\mathrm{pH}$ required for optimum enzyme activity in ZN541 strain was 6.2 , the temperature was $42^{\circ} \mathrm{C}$, the lactose concentration was $2 \%$ and the fermentation time was 24 hours. In the $\mathrm{Z} 1052$ strain, the $\mathrm{pH}$ required for optimum enzyme activity was 6.8 , the temperature was $42^{\circ} \mathrm{C}$, the lactose concentration was $4 \%$, and the fermentation time was 24 hours.

Keywords: L. delbrueckii subsp. bulgaricus, Streptococcus thermophiles, $\beta$-galactosidase, optimization.

\section{GİRİ̧̧}

Yaygin olarak laktaz olarak bilinen $\beta$ galaktosidazlar ( $\beta$-D-galaktozid galaktohidrolazlar, EC 3.2.1.23), laktozun galaktoz ve glikoz monomerlerine hidrolizini katalize eden glikozit hidrolazlardır ve gıda endüstrisindeki çeşitli biyoteknolojik süreçler için önemli bir enzimdir. Süt ve peynir altı suyunda laktoz hidrolizi için yaygın olarak kullanıldığından ticari açıdan önemlidir (Carević vd., 2015; Delgado-Fernandez vd., 2020). Hidrolitik aktivitelerine ek olarak, $\beta$-galaktosidazlar, laktozdan galakto-oligosakkaritler (GOS) oluşturmak için transgalaktozilasyon aktivitesine sahiptirler. Ayrica, laktoz intoleransı olan bireyler için düşük laktozlu ve laktozsuz süt ürünlerinin geliştirilmesi, laktoz içeren gıdaların teknolojik ve duyusal özelliklerinin iyileştirilmesi ve peynir üretim proseslerindeki peynir altı suyu yan ürünlerindeki laktoz seviyelerini azaltmak gibi uygulamaları mevcuttur (Kittibunchakul vd., 2020; Deng vd., 2020).

$\beta$-galaktosidaz enzimi kaynakları arasında bitkiler, hayvanlar ve maya, küf ve bakteri gibi mikroorganizmalar yer almaktadır (Deng vd., 2020). Biyoteknolojik uygulamalarda enzim kaynağ1 olarak Kluyveromyces marxians, $K$. lactis ve $K$. fragilis yaygin olarak kullanılmaktadır (Inchaurrondo vd., 1998). Yüksek aktiviteleri nedeniyle Bifidobacterium (B. adolescentis, B. infantis ve B. longum) (Venkateswarulu vd., 2017) ve laktik asit bakterileri (Lactiplantibacillus plantarum, Lactobacillus crispatus, L. acidopbilus, L. delbrueckii subsp. bulgaricus, Streptococcus thermophilus vb.) bakterileri de kullanilmaktadır (Gobinath ve Prapulla, 2015; Kim ve Rajagopal, 2000; Yu vd., 2020). Süt endüstrisi uygulamalarında, fermantasyon kolaylığı, yüksek enzim aktiviteleri ve iyi stabilite olmaları nedeniyle bakteriler ve özellikle laktik asit bakterileri daha çok tercih edilmektedir (Ibrahim, 2018).

$\mathrm{Bu}$ çalışmada yoğurt kaynaklı 31 Lactobacillus delbrueckii subsp. bulgaricus ve 34 Streptococcus thermophilus suşlarının öncelikle $\beta$-galaktozidaz aktivitelerinin taranması amaçlanmıştır. Daha sonra yüksek spesifik $\beta$-galaktozidaz aktiviteye sahip $L$. delbrueckii subsp. bulgaricus ZN541 ve $S$. thermophilus Z1052 suşları seçilerek, bu şuşlardan elde edilen $\beta$-galaktozidaz enzimine farklı koşulların ( $\mathrm{pH}$, sıcaklık, laktoz konsantrasyonu ve fermantasyon süresi) etkisinin belirlenerek enzim aktivitesinin yüksek olduğu optimum koşullar tespit edilmesi hedeflenmiştir.

\section{MATERYAL VE YÖNTEM}

\section{Materyal}

Çalışmada geleneksel yoğurt kaynaklı $31 \mathrm{~L}$. delbrueckii subsp. bulgaricus ve 34 S. thermophilus bakteri kültürlerine ait toplam 65 suş, Gazi Üniversitesi Fen Fakültesi Biyoloji Bölümü Biyoteknoloji Laboratuvar1 kültür koleksiyonundan temin edilmiştir. L. delbrueckii subsp. bulgaricus suşlarının geliştirilmesinde MRS besiyeri, enzim aktivitelerinin belirlenmesinde ise MRS içeriğinde bulunan glikoz yerine $\% 2$ oranında laktozun ilave edildiği Lac-MRS besiyeri kullanılmıştır. S. thermophilus suşlarının geliştirilmesinde Elliker besiyeri, enzim aktivitelerinin belirlenmesinde ise Elliker içeriğinde bulunan dekstroz yerine $\% 2$ oranında laktozun ilavesi edildiği Lac-EL besiyeri kullanılmıştır.

\section{Enzim Aktivitesi}

Bakteriler uygun besiortamlarında iki kez aktifleştirildikten sonra 5000 rpm'de $20 \mathrm{dk}$ $+4^{\circ} \mathrm{C}$ 'de santrifüj edilerek Mc Farland 6 bulanıklılığına ayarlanan kültürlerden elde edilen 
pellet $0.03 \mathrm{M}$ potasyum fosfat tamponuyla ( $\mathrm{pH}$ 6.8) yıkanmıştır. $1 \mathrm{~mL}$ tamponda çözülen bakterilerin hücre duvar1 ultrasonikasyon (50 $\mathrm{MHz}$, Vibra-Cell, Sonics\&Materials Inc. Danbury, CT marka) ile parçalanmıştır. 1000 rpm'de $10 \mathrm{dk}+4^{\circ} \mathrm{C}$ 'de santrifüjlenen örneklerden hücre atıkları uzaklaştırılmış ve süpernatant ham enzim ekstraktı olarak kullanılmışır (Zhang vd., 2012).

Bradford Reagent Kit (Amresco) kullanılarak kültürlerin protein miktarları belirlenmiştir. Standart olarak $0.0025-0.05 \mathrm{mg} / \mathrm{mL}$ arasinda değişen konsantrasyonlarda Bovine serum albumin (BSA) kullanılmıştır.

$\beta$-galaktozidaz aktivitesi soğuk şartlarda onitrofenil- $\beta$-D-galaktopiranozit (o-NPG, Sigma) substrat olarak kullanılarak tespit edilmiştir. $1 \mathrm{~mL}$ enzim ekstraktına $0.2 \mathrm{~mL} 15 \mathrm{mM}$ o-NPG içeren $0.03 \mathrm{M}$ potasyum fosfat tamponu ( $\mathrm{pH}$ 6.8) eklenmiş ve $37^{\circ} \mathrm{C}$ 'da $15 \mathrm{dk}$ inkübe edilmiştir. Reaksiyonu durdurmak için $1 \mathrm{M} 0.5 \mathrm{~mL}$ sodyum karbonat (Merck) solüsyonu ilave edilerek 1000 rpm'de $+4^{\circ} \mathrm{C}^{\prime} \mathrm{de} 10 \mathrm{dk}$ santrifüjden sonra spektrofotometre cihaz1 ile (Hitachi UV-1800) $420 \mathrm{~nm}$ dalga boyunda absorbans değeri okunmuştur. Kör olarak, ham ekstrakt yerine 1 $\mathrm{mL} 0.03 \mathrm{M}$ potasyum fosfat tamponu ( $\mathrm{pH}$ 6.8) kullanılmıştır. 1 ünite $\beta$-galaktozidaz aktivitesi dakikada $1 \mu \mathrm{mol}$ o-nitrofenolü serbest birakan enzim miktarı olarak tanımlanmıştır. Spesifik aktivite, bir miligram proteinde bulunan enzim ünite sayısı olarak kabul edilmiştir. $\beta$-galaktozidaz aktivitesi aşağıda verilen formüle göre hesaplanmıştır (Shah ve Otieno, 2007).

$$
\begin{aligned}
& \text { Enzimaktivitesi }(U / m L)=\frac{O D_{420}}{k} \times \frac{1}{t} \times\left[V_{t} / V_{e}\right] \times D \\
& \text { Spesifik aktivite }(U / m g)=\left[\frac{\text { Enzimaktivitesi }(U / m L)}{\text { Protein miktan }(m g / m L)}\right] \\
& \mathrm{Vt}=\text { Tüpte hazırlanan toplam reaksiyon hacmi } \\
& \mathrm{Ve}=\text { Küvette okutulan reaksiyon karışıınındaki enzim } \\
& \text { hacmi } \\
& \mathrm{k}=\text { Standart eğrinin eğimi } \\
& \mathrm{t}=\text { Reaksiyon zamanı } \\
& \mathrm{D}=\text { Dilüsyon faktörü }
\end{aligned}
$$

\section{Optimizasyon}

Enzim aktivitesi tespit edilen 65 suş arasında yüksek spesifik $\beta$-galaktozidaz aktivite gösteren $L$. delbrueckii subsp. bulgaricus ZN541 ve $S$. thermophilus Z1052 suşları, farklı koşulların ( $\mathrm{pH}$, sicaklik, laktoz konsantrasyonu ve fermantasyon süresi) enzim aktivitesine etkisinin belirlenmesi amacıyla seçilmiştir.

ZN541 ve Z1052 suşlarından elde edilen enzimlerin optimum aktivite gösterdiği $\mathrm{pH}$ değerini belirlemek için, $L$. delbrueckii subsp. bulgaricus ZN541 suşunda, pH's1 5.0, 6.2, 7.0 ve 8.0 değerlerine ayarlanan $0.03 \mathrm{M}$ potasyum fosfat tamponu kullanılmış ve reaksiyon $42^{\circ} \mathrm{C}$ 'de gerçekleştirilirken, S. thermophilus Z1052 suşunda tamponun pH's1 5.5, 6.8, 7.5 ve 8.5 değerlerine ayarlanarak reaksiyon gerçekleştirilmiştir (Kara, 2004). Suşlarından elde edilen enzimlerin optimum aktivite gösterdiği sıcaklı̆g belirlemek için, $1 \mathrm{~mL}$ hücre süspansiyonuna $15 \mathrm{mM} 0.2 \mathrm{~mL}$ o-NPG eklenmiş ve her iki örnekte de reaksiyon $30^{\circ} \mathrm{C}, \quad 37^{\circ} \mathrm{C}, \quad 42^{\circ} \mathrm{C}$ ve $50^{\circ} \mathrm{C}$ sicakliklarda gerçekleştirilmiştir (Ismail vd., 2010). Laktoz (substrat) konsantrasyonunun enzim aktivitesine etkisini belirlenmek için, ZN541 suşunda LacMRS besiyerine, $\% 2, \% 4, \% 6$ ve $\% 8$ oranlarında laktoz (Merck), Z1052 suşunda ise Lac-EL besiyerine $\% 2, \% 4, \% 6$ ve $\% 8$ oranlarnnda laktoz (Merck) kullanılarak enzim aktivitesi belirlenmiştir (Hsu vd., 2005). Fermantasyon süresinin enzim aktivitesine etkisini belirlenmek için ZN541 ve Z1052 suşlarından, 18, 24, 48 ve 72 saat inkübasyondan sonra elde edilen enzimlerin aktiviteleri yukarıda verilen enzim aktivitesi yöntemine göre belirlenmiştir. Enzim aktiviteleri relatif aktivite olarak aşağıdaki formüle göre hesaplanmıştır.

Relatif aktivite $(\%)=$ İncelenen parametredeki enzim aktivitesi/Optimum koşullardaki enzim aktivitesi $x 100$

\section{İstatistiksel Analiz}

Tüm çalışmalar 3 paralelli ve 3 tekerrürlü olarak yapılmış ve çalışmaların ortalama sonuçları verilmiştir. İstatistiksel analizlerde SPSS (IBM SPSS Statistics Data Editor, version 22) kullanılmıştır. Suşların enzim ve spesifik 
aktiviteleri arasında korelasyon olup olmadığ1 araştırilmasında Parametrik testlerden Pearson korelasyonu kullanılmıştır.

\section{SONUÇ ve TARTIŞMA}

$\beta$-Galaktosidaz, g1da endüstrisinde; sütün sindirilebilirliğini iyileştirmede, süt ürünlerinin tatlllı̆ı̆n, çözünürlüğünü ve lezzetini geliştirmede ve dondurulmuş konsantre tatllarda laktoz kristalizasyonunun önlenmesinde yaygin olarak kullanılmaktadır. Süt endüstrisinden sonra elde edilen hidrolize süt, laktoz intoleransı olan kissiler için yoğurt, peynir ve dondurma (konsantre tatlıar) yapımında da kullanılabilmektedir (Xin vd., 2019). $\beta$-Galaktosidaz, gıda endüstrisi dışında, ilaç endüstrisinde laktozdan kaynaklanan problemlerin hafifletilmesinde ve prebiyotik özellikleriyle bilinen galaktooligosakkaritlerin sentezi gibi birçok uygulamaları olan önemli ticari enzimlerden biridir (Gomaa, 2018). Ticari olarak çok farklı kullanım potansiyeline sahip $\beta$ Galaktosidaz enziminin en önemli kaynakları probiyotik özelliklerinden dolay1 laktik asit bakterileridir. Bu nedenden dolayı, bu çalışmada yüksek enzim aktivitesine sahip güvenilir ve yeni laktik asit bakterileri (LAB)'nin araştırılması amaçlanmıştır.

LAB'nde, $\beta$-Galaktosidaz enzimi intrasellüler bir enzim olduğundan (Carević vd., 2015; Son vd., 2017; Deng vd., 2020; Özkan vd., 2021; Mahadevaiah vd., 2020), çalş̧mamızda enzim ekstraksiyonunda bakterilerin hücre duvarını parçalamak için mekanik yöntemlerden yaygın olarak kullanılan (Carević vd., 2015) ultrasonikasyon kullanılmıştur. $31 \mathrm{~L}$. delbrueckii subsp. bulgaricus ve 34 S. thermophilus bakteri kültürlerine ait toplam 65 suşun $\beta$-galaktozidaz enziminin intrasellüler olduğunu desteklenmek amaciyla kültür süpernatantlarında da enzim aktivitesine bakılmıs ve sonikasyon uygulanmayan kültür süpernatantında aktiviteye rastlanılmamıştır. L. delbrueckii subsp. bulgaricus suşları, $0.011 \mathrm{U} / \mathrm{mL} \quad(\mathrm{ZN} 142)-0.247 \mathrm{U} / \mathrm{mL}$ (ZN541) arasındaki değişen değerlerde $\beta$ galaktozidaz aktivitesi, $0.186 \mathrm{U} / \mathrm{mg}$ (ZN142)$6.500 \mathrm{U} / \mathrm{mg}$ (ZN541) arasinda $\beta$-galaktozidaz spesifik aktivite göstermişlerdir. S. thermophilus suşlar1, $0.007 \mathrm{U} / \mathrm{mL}$ (Z14)-0.238 U/mL (Z1052) arasındaki değişen değerlerde $\beta$-galaktozidaz aktivitesi，0.172 U/mg (Z1152)-5.064 U/mg (Z1052) arasında $\beta$-galaktozidaz spesifik aktivite göstermişlerdir. L. delbrueckii subsp. bulgaricus suşlar1 arasında, ZN541 (0.247 U/mL), ZN661 $(0.149 \mathrm{U} / \mathrm{mL})$ ve $\mathrm{ZN} 641(0.121 \mathrm{U} / \mathrm{mL})$ suşları yüksek enzim aktivitesi gösterirken, $S$. thermophilus suşlar1 arasında, Z1052 (0.238 U/mL), Z752 $(0.221 \mathrm{U} / \mathrm{mL})$ ve $Z \mathrm{~N} 641(0.217 \mathrm{U} / \mathrm{mL})$ suşları yüksek enzim aktivitesi göstermiştir (Çizelge 1). Bakterilerin spesifik aktiviteleri değerlendirildiğinde, her iki türde de suşlar arasinda aktivitede önemli farkliliklar gözlemlenmiş ancak $L$. delbrueckii ssp. bulgaricus suşlarının daha yüksek spesifik aktiviteye sahip olduğu görülmüştür. Yüksek enzim aktivitesine sahip suşların yüksek spesifik aktiviteye sahip olup olmadığı istatistiksel olarak değerlendirilmiş ve $L$. delbrueckii subsp. bulgaricus suşlarının enzim ve spesifik enzim aktivitesi arasında 0.01 düzeyinde bir korelasyon tespit edilirken ve $S$. thermophilus suşlarının enzim ve spesifik enzim aktivitesi arasındaki anlamlılık düzeyi ise 0.05 olarak belirlenmiştir. Carević vd., (2015) L. delbrueckii subsp. bulgaricus ATCC 11842 suşunda 0.011 $\mathrm{IU} / \mathrm{mL}$ enzim aktivitesi olduğunu; Deng vd., (2020) ise S. thermophilus ST61 suşunda 78.85 $\mathrm{U} / \mathrm{mg}$ spesifik aktivitenin olduğunu rapor etmişlerdir. Çalışmamızda elde ettiğimiz sonuçların, diğer araştırmacıların sonuçlarından düşük olmasının nedeni, bakterilerin izolasyon kaynağ1, karbon kaynağ1, kullanılan enzim ekstraksiyon metotlarının farklılığı (sıcaklık, $\mathrm{pH}$, tampon, ekstraksiyon yöntemi, enzim ve substrat konsantrasyonu) ve aktivite hesaplanma yöntemlerindeki farklılıklar olabilir.

Geniş bir kullanım potansiyeline sahip $\beta$ galaktozidaz enziminin endüstriyel uygulamalarda kullanılabilmesi için yüksek enzim aktivitesinin yanında enzimin aktivite gösterdiği en uygun koşullarının da belirlenmesi gerekmektedir (Ismail vd., 2010; K1liç vd., 2014; Carević vdk., 2015; Deng vd., 2020). Bu amaçla çalışmamızda spesifik $\beta$-galaktozidaz enzim aktivitesi belirlenen suşlar arasından yüksek spesifik aktiviteye sahip iki suş seçilmiş (L. delbrueckii subsp. bulgaricus ZN541 ve S. thermophilus Z1052) ve farklı $\mathrm{pH}$, sicaklık, laktoz konsantrasyonları ve fermantasyon sürelerinde enzim aktiviteleri belirlenmiştir. 
Çizelge 1. L. delbrueckii subsp. bulgaricus ve $S$. thermophilus suşlarının $\beta$-galaktozidaz enzim ve spesifik aktiviteleri

Table 1. The $\beta$-galactosidase ensyme and specific activity in L. delbrueckii subsp. bulgaricus ve S. thermophilus

\begin{tabular}{|c|c|c|c|c|c|c|c|}
\hline $\begin{array}{l}\text { Bakteriler } \\
\text { Bacteria }\end{array}$ & $\begin{array}{c}\text { Protein } \\
\text { Miktar1 } \\
(\mathrm{mg} / \mathrm{mL}) \\
\text { Protein content } \\
(\mathrm{mg} / \mathrm{mL})\end{array}$ & $\begin{array}{c}\text { Enzim } \\
\text { Aktivitesi } \\
\text { (U/mL) } \\
\text { Ensyme } \\
\text { activity } \\
(\mathrm{U} / \mathrm{mL}) \\
\end{array}$ & $\begin{array}{c}\text { Spesifik } \\
\text { Aktivite } \\
\text { (U/mg) } \\
\text { Specific activity } \\
\text { (U/mg) }\end{array}$ & $\begin{array}{c}\text { Bakteriler } \\
\text { Bacteria }\end{array}$ & $\begin{array}{c}\text { Protein } \\
\text { Miktar1 } \\
(\mathrm{mg} / \mathrm{mL}) \\
\text { Protein content } \\
(\mathrm{mg} / \mathrm{mL})\end{array}$ & $\begin{array}{c}\text { Enzim } \\
\text { Aktivitesi } \\
\text { (U/mL) } \\
\text { Ensyme } \\
\text { activity } \\
(\mathrm{U} / \mathrm{mL}) \\
\end{array}$ & $\begin{array}{c}\text { Spesifik } \\
\text { Aktivite } \\
\text { (U/mg) } \\
\text { Specific activity } \\
\text { (U/mg) }\end{array}$ \\
\hline \multicolumn{4}{|c|}{ L. delbrueckii subsp. bulgaricus $(\mathrm{n}=31)^{*}$} & \multicolumn{4}{|c|}{ S. thermophilus $(n=34)^{* *}$} \\
\hline ZN171 & $0.023 \pm 0.002$ & $0.020 \pm 0.001$ & $1.150 \pm 0.002$ & Z15 & $0.024 \pm 0.001$ & $0.032 \pm 0.000$ & $0.750 \pm 0.001$ \\
\hline ZN19 & $0.019 \pm 0.003$ & $0.059 \pm 0.001$ & $0.322 \pm 0.002$ & Z14 & $0.007 \pm 0.000$ & $0.009 \pm 0.000$ & $0.778 \pm 0.000$ \\
\hline ZN141 & $0.017 \pm 0.001$ & $0.029 \pm 0.003$ & $0.586 \pm 0.002$ & Z151 & $0.217 \pm 0.000$ & $0.096 \pm 0.000$ & $2.260 \pm 0.000$ \\
\hline ZN172 & $0.042 \pm 0.000$ & $0.025 \pm 0.000$ & $1.680 \pm 0.000$ & Z18 & $0.009 \pm 0.000$ & $0.025 \pm 0.000$ & $0.360 \pm 0.000$ \\
\hline ZN18 & $0.036 \pm 0.003$ & $0.059 \pm 0.002$ & $0.610 \pm 0.003$ & Z173 & $0.063 \pm 0.002$ & $0.074 \pm 0.002$ & $0.851 \pm 0.002$ \\
\hline ZN142 & $0.011 \pm 0.000$ & $0.059 \pm 0.001$ & $0.186 \pm 0.001$ & Z171 & $0.034 \pm 0.000$ & $0.059 \pm 0.001$ & $0.576 \pm 0.001$ \\
\hline ZN252 & $0.033 \pm 0.000$ & $0.024 \pm 0.002$ & $1.375 \pm 0.001$ & $\mathrm{Z} 272$ & $0.088 \pm 0.000$ & $0.074 \pm 0.000$ & $1.189 \pm 0.000$ \\
\hline ZN272 & $0.021 \pm 0.000$ & $0.041 \pm 0.000$ & $0.512 \pm 0.000$ & Z261 & $0.014 \pm 0.000$ & $0.041 \pm 0.000$ & $0.341 \pm 0.000$ \\
\hline ZN251 & $0.048 \pm 0.000$ & $0.068 \pm 0.000$ & $0.706 \pm 0.000$ & $\mathrm{Z} 271$ & $0.018 \pm 0.000$ & $0.041 \pm 0.000$ & $0.439 \pm 0.000$ \\
\hline ZN281 & $0.054 \pm 0.000$ & $0.041 \pm 0.000$ & $1.317 \pm 0.000$ & Z372 & $0.112 \pm 0.000$ & $0.089 \pm 0.000$ & $1.317 \pm 0.000$ \\
\hline ZN362 & $0.030 \pm 0.003$ & $0.034 \pm 0.003$ & $0.883 \pm 0.003$ & Z361 & $0.030 \pm 0.003$ & $0.034 \pm 0.000$ & $1.258 \pm 0.002$ \\
\hline ZN382 & $0.029 \pm 0.000$ & $0.054 \pm 0.001$ & $0.537 \pm 0.001$ & Z351 & $0.092 \pm 0.000$ & $0.045 \pm 0.000$ & $2.044 \pm 0.000$ \\
\hline ZN341 & $0.039 \pm 0.004$ & $0.043 \pm 0.002$ & $0.907 \pm 0.003$ & Z472 & $0.096 \pm 0.000$ & $0.067 \pm 0.002$ & $1.433 \pm 0.001$ \\
\hline ZN342 & $0.018 \pm 0.000$ & $0.032 \pm 0.000$ & $0.563 \pm 0.000$ & Z482 & $0.104 \pm 0.000$ & $0.082 \pm 0.000$ & $1.268 \pm 0.000$ \\
\hline ZN361 & $0.015 \pm 0.000$ & $0.026 \pm 0.003$ & $0.577 \pm 0.002$ & Z662 & $0.052 \pm 0.000$ & $0.062 \pm 0.000$ & $1.339 \pm 0.000$ \\
\hline ZN461 & $0.095 \pm 0.000$ & $0.041 \pm 0.001$ & $2.302 \pm 0.001$ & Z651 & $0.083 \pm 0.000$ & $0.062 \pm 0.000$ & $0.839 \pm 0.000$ \\
\hline ZN442 & $0.082 \pm 0.000$ & $0.062 \pm 0.003$ & $1.323 \pm 0.002$ & Z672 & $0.105 \pm 0.000$ & $0.091 \pm 0.000$ & $1.150 \pm 0.000$ \\
\hline ZN471 & $0.021 \pm 0.005$ & $0.031 \pm 0.002$ & $0.677 \pm 0.003$ & Z682 & $0.069 \pm 0.000$ & $0.080 \pm 0.000$ & $0.862 \pm 0.000$ \\
\hline ZN552 & $0.015 \pm 0.001$ & $0.027 \pm 0.000$ & $0.556 \pm 0.001$ & $\mathrm{Z} 752$ & $0.221 \pm 0.000$ & $0.071 \pm 0.000$ & $3.113 \pm 0.000$ \\
\hline ZN572 & $0.061 \pm 0.000$ & $0.042 \pm 0.000$ & $1.452 \pm 0.000$ & Z743 & $0.052 \pm 0.000$ & $0.073 \pm 0.000$ & $0.712 \pm 0.000$ \\
\hline ZN551 & $0.018 \pm 0.001$ & $0.026 \pm 0.001$ & $0.692 \pm 0.001$ & Z861 & $0.014 \pm 0.000$ & $0.034 \pm 0.000$ & $0.412 \pm 0.000$ \\
\hline ZN543 & $0.021 \pm 0.004$ & $0.043 \pm 0.000$ & $0.553 \pm 0.002$ & Z862 & $0.088 \pm 0.001$ & $0.080 \pm 0.001$ & $1.100 \pm 0.001$ \\
\hline ZN541 & $0.247 \pm 0.000$ & $0.038 \pm 0.001$ & $6.500 \pm 0.000$ & Z1062 & $0.009 \pm 0.001$ & $0.043 \pm 0.001$ & $0.209 \pm 0.001$ \\
\hline ZN662 & $0.022 \pm 0.001$ & $0.059 \pm 0.001$ & $0.373 \pm 0.001$ & Z1083 & $0.120 \pm 0.000$ & $0.098 \pm 0.000$ & $1.224 \pm 0.000$ \\
\hline ZN661 & $0.149 \pm 0.000$ & $0.071 \pm 0.001$ & $2.099 \pm 0.001$ & Z1061 & $0.098 \pm 0.001$ & $0.095 \pm 0.001$ & $1.032 \pm 0.001$ \\
\hline ZN652 & $0.073 \pm 0.000$ & $0.058 \pm 0.001$ & $1.259 \pm 0.001$ & Z1081 & $0.049 \pm 0.000$ & $0.091 \pm 0.000$ & $0.538 \pm 0.000$ \\
\hline ZN641 & $0.121 \pm 0.000$ & $0.043 \pm 0.004$ & $2.814 \pm 0.002$ & Z1051 & $0.039 \pm 0.000$ & $0.081 \pm 0.001$ & $0.481 \pm 0.001$ \\
\hline ZN672 & $0.096 \pm 0.000$ & $0.034 \pm 0.001$ & $2.823 \pm 0.001$ & Z1052 & $0.238 \pm 0.000$ & $0.047 \pm 0.000$ & $5.064 \pm 0.000$ \\
\hline ZN82 & $0.061 \pm 0.001$ & $0.038 \pm 0.001$ & $1.605 \pm 0.001$ & Z1161 & $0.072 \pm 0.000$ & $0.056 \pm 0.001$ & $1.288 \pm 0.001$ \\
\hline ZN942 & $0.097 \pm 0.000$ & $0.067 \pm 0.002$ & $1.448 \pm 0.001$ & Z1152 & $0.010 \pm 0.001$ & $0.058 \pm 0.001$ & $0.172 \pm 0.001$ \\
\hline \multirow[t]{4}{*}{ ZN951 } & $0.124 \pm 0.000$ & $0.071 \pm 0.000$ & $1.746 \pm 0.001$ & Z1171 & $0.107 \pm 0.000$ & $0.067 \pm 0.000$ & $1.597 \pm 0.000$ \\
\hline & & & & Z1151 & $0.054 \pm 0.000$ & $0.081 \pm 0.000$ & $0.667 \pm 0.000$ \\
\hline & & & & Z1153 & $0.084 \pm 0.000$ & $0.081 \pm 0.000$ & $1.037 \pm 0.000$ \\
\hline & & & & Z1162 & $0.100 \pm 0.000$ & $0.064 \pm 0.000$ & $1.563 \pm 0.000$ \\
\hline
\end{tabular}

$* P<0.01$ düzeyinde anlamlı (Korelasyon)

** $P<0.05$ düzeyinde anlamlı (Korelasyon) 
ß-Galaktosidazların optimum çalısma pH'ları, kaynaklarına bağlı olarak büyük ölçüde değişebilmektedir. Genel olarak, $\mathrm{pH}$ profillerine göre asidik $\beta$-galaktosidazlar (mantarlarda) ve nötr $\beta$-galaktosidazlar (bakterilerde ve mayalarda) olarak iki gruba ayrilabilirler (Panesar ve ark., 2010). pH, enzimle katalize edilen bir reaksiyonun hızını etkilediği için, bir enzimin aktivitesi ve stabilitesi üzerindeki etkisini bilmek gerekmektedir. L. delbrueckii subsp. bulgaricus ZN541 suşunda, farklı pH'lardaki $(\mathrm{pH}$ 5.0, 6.2, 7.0, 8.0) enzim aktivitesinin sirasiyla, $0.148 \mathrm{U} / \mathrm{mL}$ (relatif aktivite: \%60), $0.247 \mathrm{U} / \mathrm{mL}$ (5100), 0.218 $\mathrm{U} / \mathrm{mL}(\% 88)$ ve $0.119(\% 48) \mathrm{U} / \mathrm{mL}$ olduğu belirlenmiştir. ZN541 suşundan elde edilen $\beta$ galaktozidaz enziminin optimum aktivite gösterdiği pH değeri 6.2 olarak bulunmuştur (Şekil 1). S. thermophilus Z1052 suşunda, pH 5.5, $6.8,7.5$ ve 8.5 'de $\beta$-galaktozidaz enzim aktivitesi sirasiyla, $0.145 \mathrm{U} / \mathrm{mL}$ (relatif aktivite: \%61), 0.238
$\mathrm{U} / \mathrm{mL}(\% 100), 0.189 \mathrm{U} / \mathrm{mL}(\% 79)$ ve 0.086 $\mathrm{U} / \mathrm{mL}$ (\%36) olarak tespit edilmiştir. Z1052 suşundan elde edilen $\beta$-galaktozidaz enziminin optimum aktivite gösterdiği $\mathrm{pH}$ değeri 6.8 olarak bulunmuştur (Şekil 2). Optimum $\mathrm{pH}$ değerinden asidik ve alkali ortamlarda relatif aktivitede düşüş gözlenmiştir. Çalışmamızda elde ettiğimiz sonuçlara benzer şekilde, enzimin en aktif olduğu $\mathrm{pH}$ değerinin, L. acidophilus için 6.8 (Carevıć vd., 2015), S. thermophilus 95/2 suşu için $\mathrm{pH} 7.0, \mathrm{~L}$. bulgaricus 77 suşu için $\mathrm{pH}$ 7.0-7.5 arasinda (Ustok vd., 2010) ve Lactococcus lactis için $\mathrm{pH} \quad 6.0$ (Mozumder vd., 2012) olduğu rapor edilmiştir. L. delbrueckii subsp. bulgaricus ZN541 (pH 6.2) ve $S$. thermophilus Z1052 (pH 6.8) suşlarından elde edilen $\beta$-galaktozidaz enzimi nötr $\mathrm{pH}$ 'a yakın değerlerde yüksek relatif aktivite gösterdiklerinden, sütte $(\mathrm{pH}$ 6.6) ve peynir altı suyunda ( $\mathrm{pH}$ 6.2) laktozun hidrolizinde kullanım potansiyeline sahip olabilecekleri düşünülmüştür.

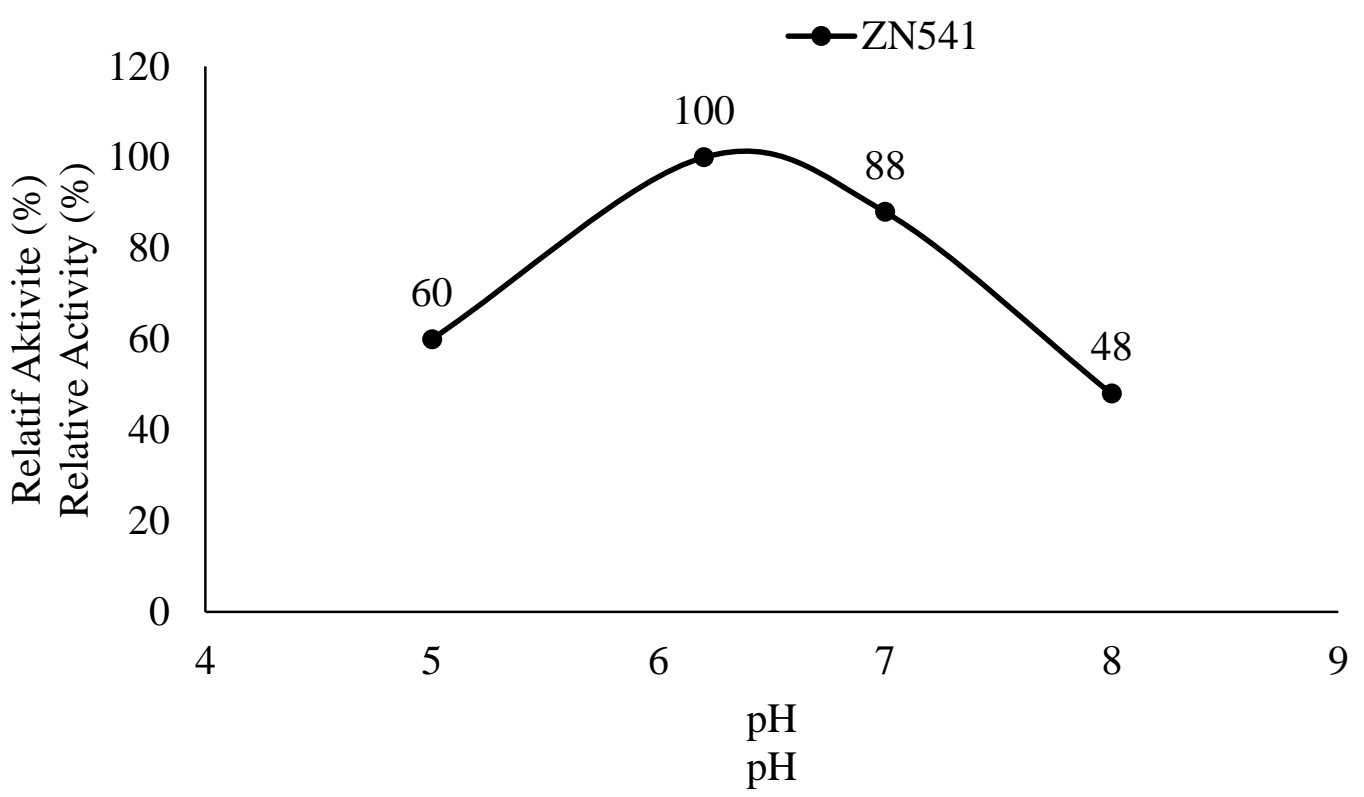

Şekil 1. L. delbrueckii subsp. bulgaricus ZN541'den elde edilen $\beta$-galaktozidaz enzimine pH'in etkisi Figure 1. Effect of $p H$ on $\beta$-galactosidase ensyme activity in L. delbrueckii subsp. bulgaricus ZN541 


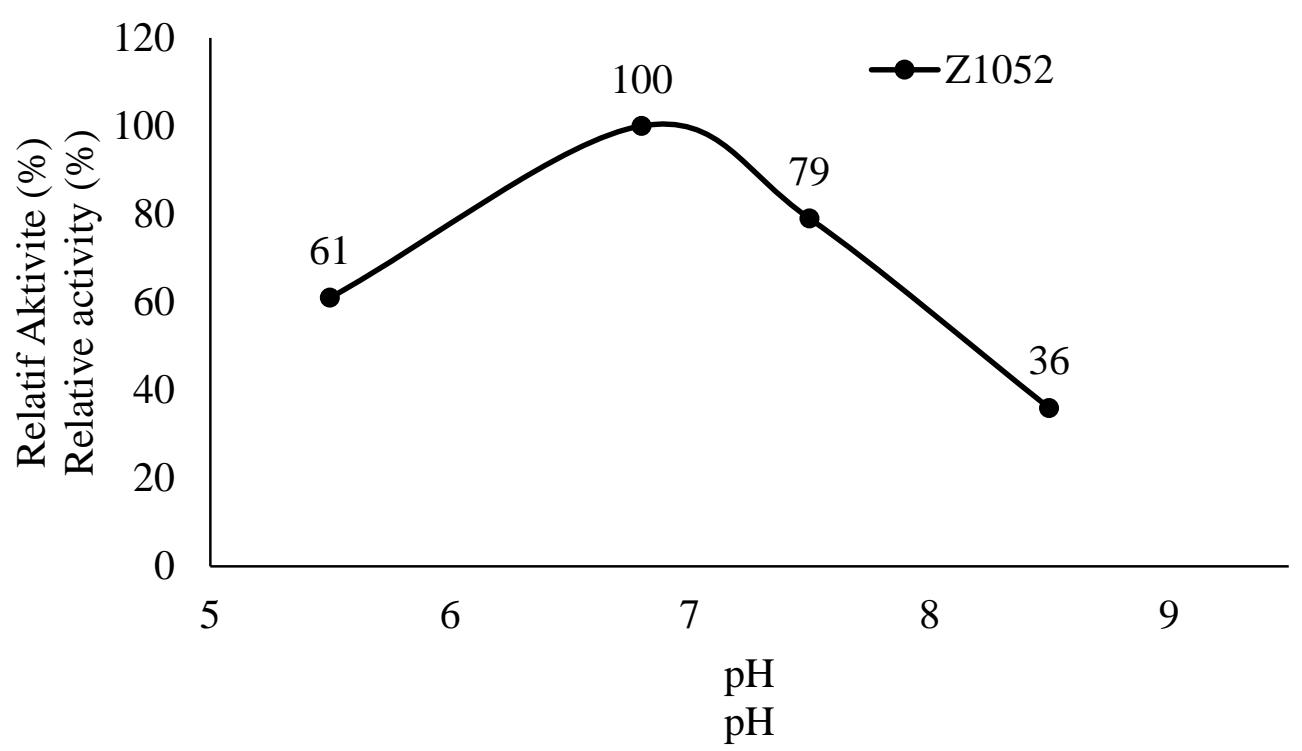

Şekil 2. S. thermophilus Z1052'den elde edilen $\beta$-galaktozidaz enzimine $\mathrm{pH}$ 'in etkisi

Figure 2. Effect of $p H$ on $\beta$-galactosidase ensyme activity in $\mathrm{S}$. thermophilus $Z 1052$

Bakterilerden elde edilen $\beta$-galaktosidazın kullanım kaynağını belirlemedeki seçim kriterlerinden biri de reaksiyon sicaklığıdır (Mahadevaiah vd., 2020). Reaksiyon süresi, pH, enzimin elde edildiği kaynak, substrat gibi birçok faktör enzimin optimum sıcaklığını etkilemektedir (Ustok vd., 2010). L. delbrueckii subsp. bulgaricus ZN541 suşunda enzim aktivitesi, $30^{\circ} \mathrm{C}$ 'de 0.055 $\mathrm{U} / \mathrm{mL}$ (relatif aktivite: $\% 22$ ), $37^{\circ} \mathrm{C}^{\prime}$ de 0.184 $\mathrm{U} / \mathrm{mL}(\% 74), 42^{\circ} \mathrm{C}^{\prime}$ de $0.247 \mathrm{U} / \mathrm{mL}(\% 100)$ ve $50^{\circ} \mathrm{C}$ 'de $0.097 \mathrm{U} / \mathrm{mL}(\% 75)$ olduğu belirlenmiştir (Şekil 3). S. thermophilus Z1052 suşunda enzim aktivitesi, $30^{\circ} \mathrm{C}$ 'de $0.120 \mathrm{U} / \mathrm{mL}$ (relatif aktivite: $\% 50), 37^{\circ} \mathrm{C}^{\prime}$ de $0.144 \mathrm{U} / \mathrm{mL}(\% 61), 42^{\circ} \mathrm{C}$ 'de 0.238 $\mathrm{U} / \mathrm{mL}(\% 100)$ ve $50^{\circ} \mathrm{C}$ de $0.178 \mathrm{U} / \mathrm{mL}(\% 39)$ tespit edilmiştir. Her iki suşdan elde edilen enzimin optimum sicaklık değeri $42^{\circ} \mathrm{C}$ olarak belirlenmiştir. Enzimlerin relatif aktivitesinin $30^{\circ} \mathrm{C}$ 'de en düşük değerde olduğu görülmüştür (Şekil 3). Benzer şekilde, farklı laktik asit bakterileri ile yapilan çalışmalarda, $\beta$ galaktozidazın en aktif olduğu sicaklığın, $L$. crispatus ATCC 33820 için $45^{\circ} \mathrm{C}$ (Kim ve Rajagopal, 2000), yoğurttan izole edilen $S$. thermophilus suşu için $40^{\circ} \mathrm{C}$ (Princely vd., 2013), L. plantarum 70810 suşu için $60^{\circ} \mathrm{C}$ (Zhang vd., 2013) ve $S$. thermophilus $95 / 2$ suşu için $50^{\circ} \mathrm{C}, L$. bulgaricus 77 suşu için $45^{\circ} \mathrm{C}$ (Ustok vd., 2010) olduğu rapor edilmiştir. Süt endüstrisinde laktozun hidrolizinde yüksek sicakliklarda istenmeyen mikroorganizmalar çoğalmadan $\beta$-galaktozidaz elde edilebileceğinden çalışmamızda belirlenen yüksek sıcaklıklarda enzim aktivitelerinin fazla olması bir avantaj olarak değerlendirilmiştir.

LAB'de $\beta$-galaktosidaz üretimi için substrat konsantrasyonu, enzimin reaksiyon hızını arttıran en önemli faktörlerden birisidir (Deng vd., 2020). Lac baskılayıcı proteinine bağlanarak lacZ geninin ekspresyonunu destekleyen ve bu proteinin lac operonun operatör bölgesine bağlanmasını engelleyen laktoz, $\beta$-galaktosidaz sentezini uyaran optimum karbon kaynağıdır (Wheatley vd., 2013). $\mathrm{Bu}$ nedenle bu çalışmada substrat kaynağı olarak laktoz kullanılmış ve farklı konsantrasyonlardaki laktozun (\%2, 4, 6 ve 8$)$ enzim aktivitesine etkisi rapor edilmiştir. L. delbrueckii ssp. bulgaricus ZN541 suşunda, farklı laktoz konsantrasyonlarındaki enzim aktivitesinin sırasıla, 0.247 $\mathrm{U} / \mathrm{mL}$ (relatif aktivite: \%100), $0.155 \mathrm{U} / \mathrm{mL}$ (\%62), $0.134 \mathrm{U} / \mathrm{mL}(\% 54)$ ve $0.121 \mathrm{U} / \mathrm{mL}(\% 49)$; Z1052 suşunda ise sırasıyla, $0.136 \mathrm{U} / \mathrm{mL}$ (relatif aktivite: \%57), $0.238 \mathrm{U} / \mathrm{mL}(\% 100), 0.142 \mathrm{U} / \mathrm{mL}$ (\%60) ve $0.137 \mathrm{U} / \mathrm{mL}(\% 58)$ olarak belirlenmiştir. ZN541 suşundan elde edilen enzimin optimum laktoz konsantrasyonu \%2, Z1052 suşundan elde edilen enziminin optimum laktoz konsantrasyonu ise $\% 4$ olarak tespit edilmiştir. ZN541 suşundan 
elde edilen enzimde, laktoz konsantrasyonu arttıkça relatif aktivitenin düştüğü görülmüştür (Şekil 4). Kılıç (2013), L. fermentum ZYN17 ve L. acidophilus BAZ36 suşları için \%4, L. casei LB65 ve L. rbamnosus GD11 suşları için \%2 oranında laktozun enzim aktivitesinin en uygun, Akolkar vd., (2005) L. acidophilus suşundan elde ettikleri $\beta$ Șekil 4 galaktozidaz enziminin maksimum $\beta$-galaktozidaz aktivitesini \%1,5 laktoz konsantrasyonunda ve Zhang vd., (2013), L. plantarum 70810 suşunun ise \%4 laktoz konsantrasyonunda aktivitenin yüksek olduğunu rapor etmişlerdir. Yapılan çalışmalarda, $\beta$-galaktozidaz enzim aktivitesi farklı laktoz konsantrasyonlarında farklılık göstermiştir.

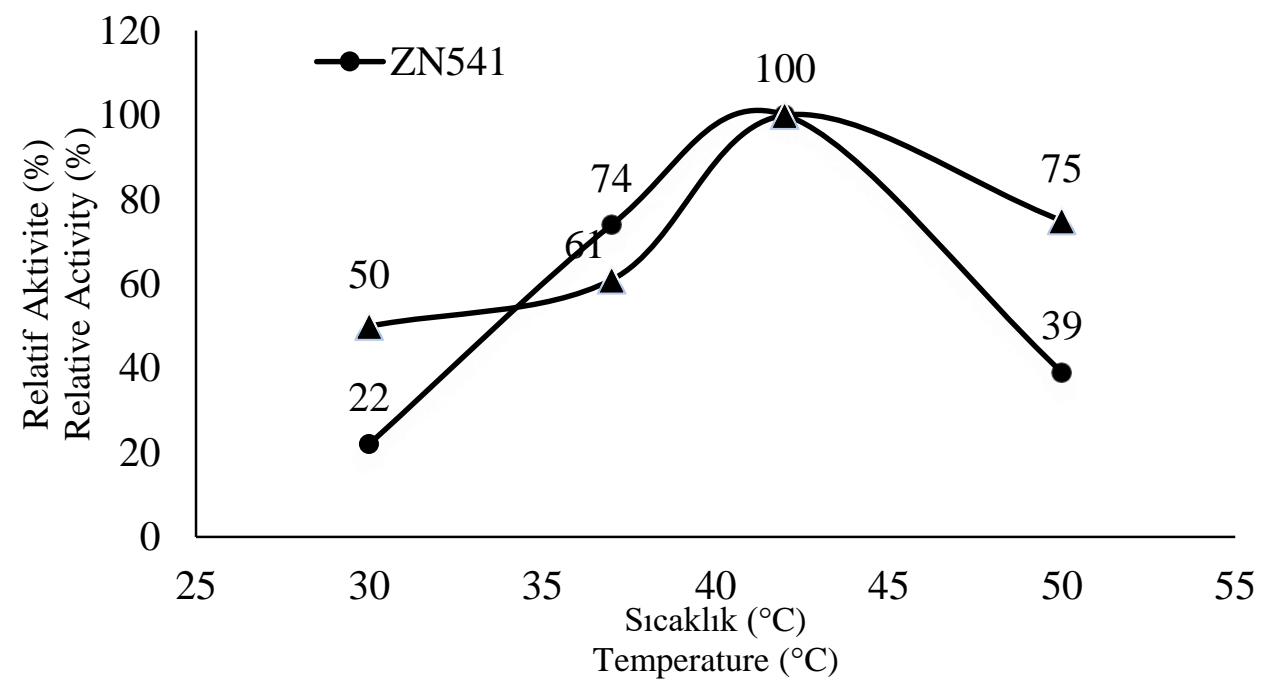

Şekil 3. L. delbrueckii subsp. bulgaricus ZN541 ve S. thermophilus Z1052 suşlanndan elde edilen $\beta$ galaktozidaz enzimine sicakliğın etkisi

Figure 3. Effect of temperature on $\beta$-galactosidase ensyme in L. delbrueckii subsp. bulgaricus ZN541 and $\mathrm{S}$. thermophilus Z1052

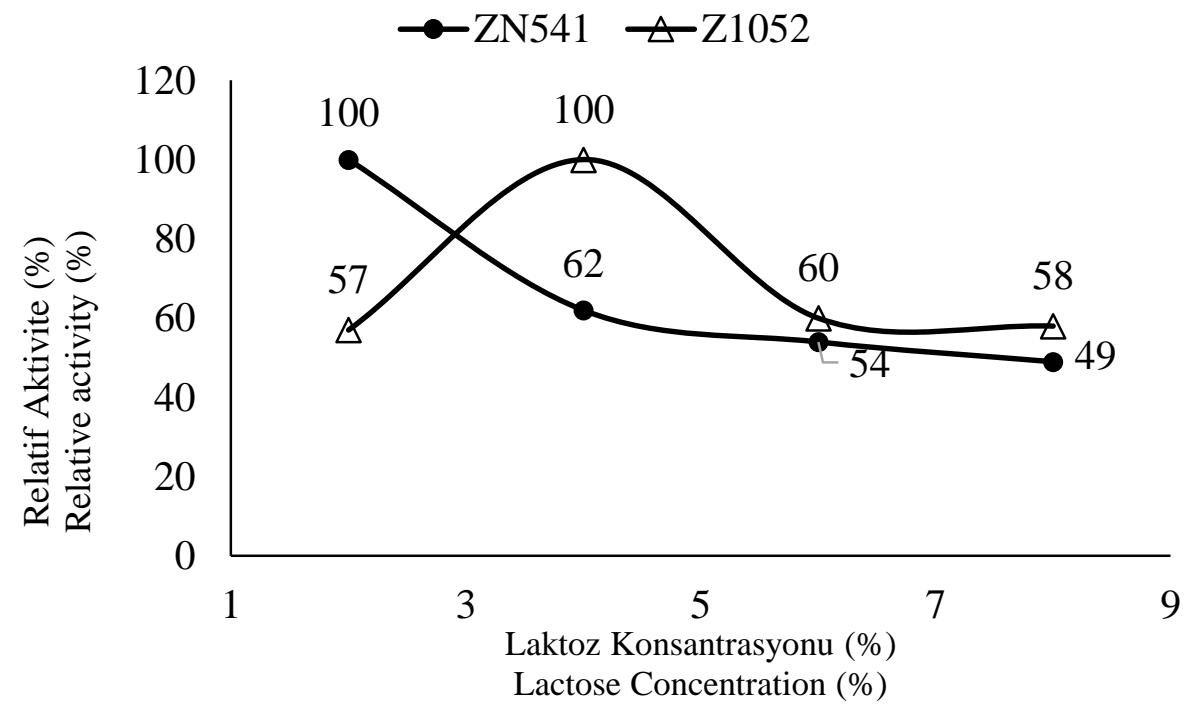

Şekil 4. L. delbrueckii subsp. bulgaricus ZN541 ve S. thermophilus Z1052 suşlarından elde edilen $\beta$ galaktozidaz enzimine laktoz konsantrasyonunun etkisi

Figure 4. Effect of lactose concentration on $\beta$-galactosidase ensyme in L. delbrueckii subsp. bulgaricus ZN541 and S. thermophilus Z1052 
Mikroorganizmaların metabolik aktiviteleri üzerinde, fermantasyon süresi önemli bir etkiye sahiptir. Bakterilerin fermantasyon süresinin k1sa olması enzim üretim maliyetini azaltan bir faktör olarak değerlendirilmektedir (Serin ve Akcan, 2019). L. delbrueckii subsp. bulgaricus ZN541 suşunda, enzim aktivitesi 18. saatte $0.074 \mathrm{U} / \mathrm{mL}$ (relatif aktivite: \%30), 24. saatte $0.247 \mathrm{U} / \mathrm{mL}$ (\%100), 42. saatte $0.201 \mathrm{U} / \mathrm{mL}(\% 81)$ ve 72. saatte $0.084 \mathrm{U} / \mathrm{mL}$ (\%34) olduğu belirlenirken, $S$. thermophilus Z1052 suşunda enzim aktivitesi 18. saatte $0.095 \mathrm{U} / \mathrm{mL}(\% 40), 24$. saatte $0.238 \mathrm{U} / \mathrm{mL}$ (\%100), 42. saatte $0.154 \mathrm{U} / \mathrm{mL}(\% 65)$ ve 72. saatte $0.157 \mathrm{U} / \mathrm{mL}(\% 66)$ olarak tespit edilmiştir. ZN541 ve Z1052 suşlarından elde edilen enzimlerin optimum enzim aktivitesi için gereken fermantasyon süresinin 24 saat olduğu belirlenmiştir. Her iki suştan elde edilen enzimlerin relatif aktivitenin 18. saatte en düşük değerde olduğu görülmüştür (Şekil 5). Benzer şekilde, Makwana vd., (2017) 10 Lactobacillus kültüründe $\beta$-galaktozidaz aktivitenin 24 . saatte 48. ve 72. saate göre daha yüksek olduğunu, Carevıć vd., (2015) L. acidophilus suşunda 48. saatte enzim aktivitesinin maksimum düzeyde olduğunu ve soya içeceğinden (Das vd., 2020) izole edilen 8 Lactobacillus suşunun, optimum enzim aktivitesini 24. saatte gösterdiklerini bildirmişlerdir. Birçok bakterinin maksimum $\beta$-galaktozidaz enzim üretimini durgunluk fazının başlangıcında gösterdiği rapor edilmektedir (Carevıć vd., 2015; Alves vd., 2010). Bu durum, durgunluk fazında, ortamda bulunan laktoz hidrolizinin sonucu olarak düşük laktoz konsantrasyonu ve daha büyük miktarlarda serbest glikozun, $\beta$ galaktozidaz üretiminin baskılanmasına neden olduğu şeklinde yorumlanmıştır (Murad vd., 2011). Çalışmamızdaki her iki bakterilerinin de enzim aktivitesinin durgunluk fazının başlangıcında yüksek çıktığı görülmüştür.

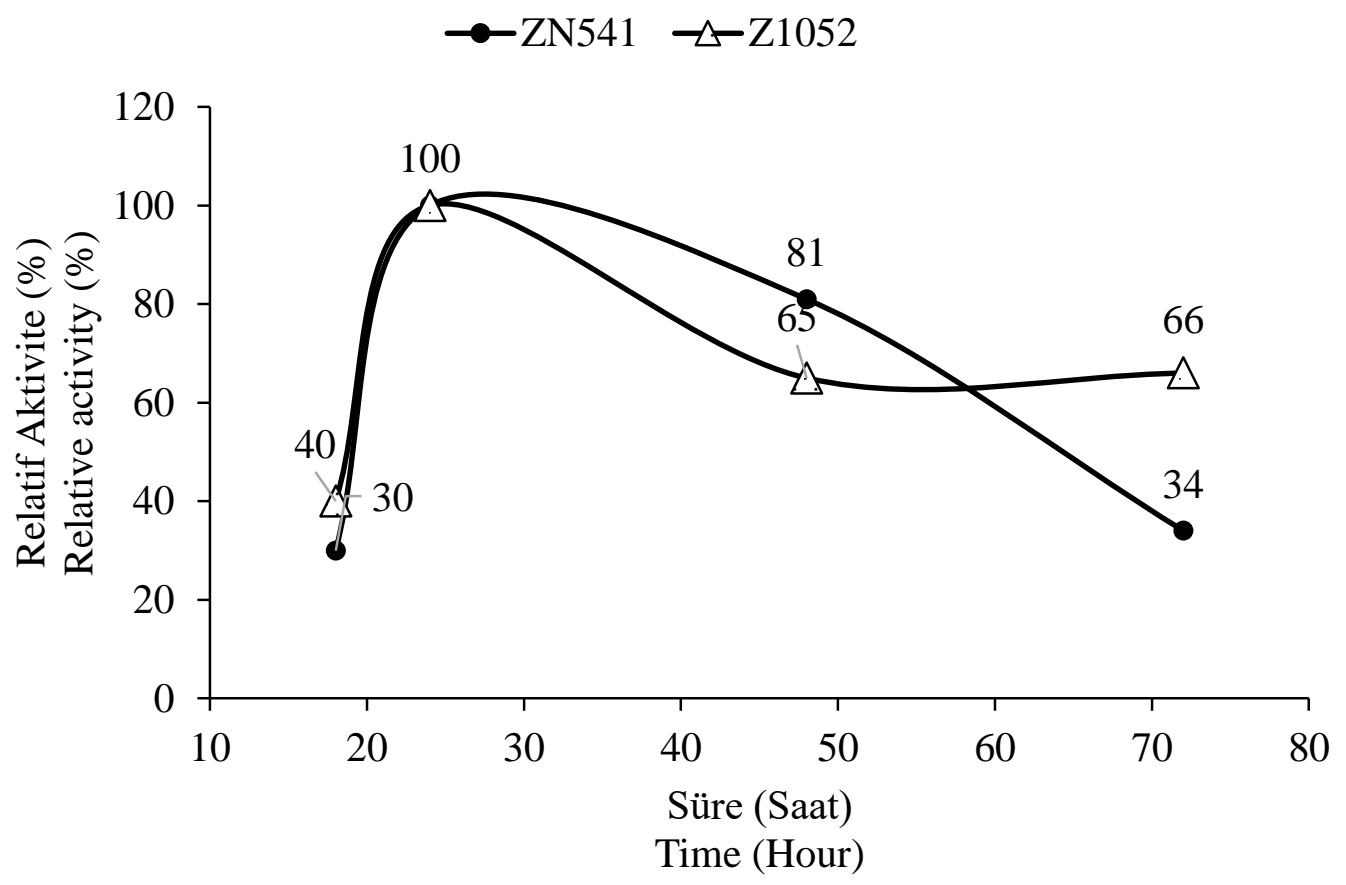

Şekil 5. L. delbrueckii subsp. bulgaricus ZN541 ve S. thermophilus Z1052 suşlarından elde edilen $\beta$ galaktozidaz enzimine fermantasyon süresinin etkisi

Figure 5. Effect of fermentation time on $\beta$-galactosidase ensyme in L. delbrueckii subsp. bulgaricus ZN541 and S. thermophilus Z1052 
Bu çalışmada, $\beta$-galaktozidaza duyulan endüstriyel ilgiden dolayı, yoğurt kaynaklı $L$. delbrueckii ssp. bulgaricus ve $S$. thermophilus suşlarının $\beta$ galaktozidaz üretimi için potansiyel kaynak olabilirliği araştırılmıştır. Optimizasyon çalışmalarından elde edilen sonuçlar doğrultusunda, bakterilerimizden elde edilen enzimlerin biyoteknolojik uygulamalar için umut verici adaylar olabileceği düşünülmüştür.

\section{ÇIKAR ÇATIŞMASI}

Yazarların makale ile ilgili başka kişiler veya kurumlar ile çıkar çatışması bulunmamaktadır.

\section{YAZAR KATKILARI}

ZY ve HY, araştırmanın planlanmasi, yürütülmesi, değerlendirilmesi ve yazımında görev almıştır.

\section{TEŞEKKÜR}

Gazi Üniversitesi Akademik Yazma Uygulama Ve Araştırma Merkezi'ne makalenin İngilizce dil bilgisini kontrol ettiği için teşekkür ederiz.

\section{KAYNAKLAR}

Alves, F.G., Filho, F., Medeiros Burkert, J., Kalil, S. 2010. Maximization of $\beta$-Galactosidase production: A simultaneous investigation of agitation and aeration effects. ApplBiochem Biotech, 160, 1528-1539. doi: 10.1007/s12010-009-8683-z

Akolkar, S.K., Sajgure, A., Lele, S.S. 2005. Lactase Production from Lactobacillus acidophilus. World J Microbiol Biotechnol, 21, 1119-1122. doi: 10.1007/s11274-005-0079-9

Carević, M., Vukašinović-Sekulić, M., Grbavčić, S., Stojanović, M., Mihailović, M. Dimitrijević, A., Bezbradica, D. 2015. Optimization of $\beta$ galactosidase production from lactic acid bacteria. Hem Ind, 69 (3), 305-312. doi: 10.2298/HEMIND140303044C

Das, S., Mishra B.K., Hati, S. 2020. Effect of nutritional factors on growth behaviour, proteolytic, $\beta$-glucosidase and $\beta$-galactosidase activities of Lactobacillus cultures during soy-drink fermentation. Curr Res Nut Food Sci, 8 (3), 877-888. doi: http://dx.doi.org/10.12944/CRNFSJ.8.3.18
Delgado-Fernandez, P., Plaza-Vinuesa, L., Lizasoain-Sánchez, S., de las Rivas, B., Muñoz, R., Jimeno, M.L., García-Doyagüez, E., Moreno, F.J., Corzo, N. 2020. Hydrolysis of lactose and transglycosylation of selected sugar alcohols by LacA $\beta$-galactosidase from Lactobacillus plantarum WCFS1. J Agric Food Chem, 68, 7040-7050. doi.org/10.1021/acs.jafc.0c02439

Deng, Y., Xu, M., Ji, D., Agyei, D. 2020. Optimization of $\beta$-galactosidase production by batch cultures of Lactobacillus leichmannii 313 (ATCC 7830). Ferment, 6, 27. doi.org/10.3390/fermentation6010027

Gobinath, D. and Prapulla, S.G. 2015. Transgalactosylating $\beta$-galactosidase from probiotic Lactobacillus plantarum MCC2156: Production and permeabilization for use as whole cell biocatalyst. J Food Sci Technol-Mysore, 52 (9), 6003-6009. doi:10.1007/s13197-014-1656-4

Gomaa, E.Z. 2018. Beta-galactosidase from Lactobacillus delbrueckii and Lactobacillus reuteri: Optimization, characterization and formation of galactooligosaccharides. Indian J Biotechnol, 17 (3), 407-415.

Hsu, C.A., Yu, R.C., Chou, C.C. 2005. Production of $\beta$-galactosidase by Bifidobacteria as influenced by various culture conditions. Int J Food Microbiol, 104 (2), 206. doi.org/10.1016/j.ijfoodmicro.2005.02.010

Ibrahim, A.H. 2018. Enhancement of $\beta$ galactosidase activity of lactic acid bacteria in fermented camel milk. Emirates J Food Agric, 30 (4), 256-267. doi: 10.9755/ejfa.2018.v30.i4.1660

Inchaurrondo, V.A., Flores, M.V., Voget, C.E. 1998. Growth and $\beta$-galactosidase synthesis in aerobic chemostat cultures of Kluyveromyces lactis. J Ind Microbiol Biotechnol, 20, 291-298.

Ismail, S.A.A., El-Mohamady, Y., Helmy, W.A., Abou-Romia, R., Hashem, A.M. 2010. Cultural condition affecting the growth and production of $\beta$-galactosidase by Lactobacillus acidophilus NRRL 4495. Aust J Basic Appl Sci, 4 (10), 5051-5058.

Kara F. 2004. Release and characterization of beta-galactosidase from Lactobacillus plantarum. 
M.C. Thesis, Department of Biotechnology, Middle East Technical University, 89p.

K1lıç, Y. 2013. Lactobacillus ve Bifidobacterium cinsi bakterilerin beta galaktosidaz enzim aktiviteleri. Gazi Üniversitesi Fen Bilimleri Enstitüsü Biyoloji Anabilim Dalı Yüksek Lisans Tezi, Ankara, Türkiye, $103 \mathrm{~s}$.

Kilıç, Y., Yüksekdağ, Z.N., Yüksekdağ, H. 2014. Lactobacillus ve Bifidobacterium cinsi bakterilerin beta galaktosidaz enzim aktivitelerinin belirlenmesi. GIDA, 39 (4), 211-218. doi: 10.5505/gida.29491

Kim, J.W. and Rajagopal, S.N. 2000. Isolation and characterization of $\beta$-galactosidase from Lactobacillus crispatus. Folia Microbiol, 45, 29-34. doi: 10.1007/BF02817446

Kittibunchakul, S., van Leeuwen, S.S., Dijkhuizen, L., Haltrich, D., Nguyen. T.H. 2020. Structural comparison of different galactooligosaccharide mixtures formed by $\beta$-Galactosidases from Lactic Acid Bacteria and Bifidobacteria. J Agric Food Chem, 68, 4437-4446. doi.org/10.1021/acs.jafc.9b08156

Mahadevaiah, S., Basavaiah, R., Parida, M., Batra, H.V. 2020. Optimal production of $\beta$-galactosidase from Lactobacillus fermentum for the synthesis of prebiotic galactooligosaccharides (GOS). J Pure Appl Microbiol, 14(4), 2769-2780. doi.org/10.22207/JPAM.14.4.53

Makwana, S., Hati, S., Parmar, H., Aparnathi, K.D. 2017. Process optimization for the production of $\beta$-galactosidase using potential Lactobacillus cultures. Int J Curr Microbiol Appl Sci, 6(8), 1454-1469. doi:10.20546/ijcmas.2017.608.176

Mozumder, N.H.M.R., Akhtaruzzaman, M., Bakr, M.A., Tuj-Zohra, F. 2012. Study on isolation and partial purification of lactase ( $\beta$-galactosidase) enzyme from Lactobacillus bacteria isolated from yogurt. J Sci Res, 4 (1), 239-249. doi: https://doi.org/10.3329/jsr.v4i1.8478

Murad, H.A., Refaea, R.I., Aly, E.M. 2011. Utilization of UF-permeate for production of $\beta$ galactosidase by Lactic Acid Bacteria. Pol J
Microbiol, 60, 139-144. doi:10.33073/pjm-2011019

Özkan, E.R., Demirci, T, Öztürk, H.İ., Akına, N. 2021. Screening Lactobacillus strains from artisanal Turkish goatskin casing Tulum cheeses produced by nomads via molecular and in vitro probiotic characteristics. J SciFood Agric, 101 (7), 2799-2808. doi 10.1002/jsfa.10909

Panesar, P.S., Kumari, S., Panesar, R. 2010. Potential applications of immobilized $\beta$ galactosidase in food processing industries. Ensyme Res, 473137. doi: 10.4061/2010/473137

Princely, S., Basha, N.S., Kirubakaran, J.J., Dhanaraju, M.D. 2013. Biochemical characterization, partial purification, and production of an intracellular beta-galactosidase from Streptococcus thermophilus grown in whey. Eur $J$ Exp Biol, 3(2), 242-251.

Serin, B ve Akcan, N. 2019. Katı faz fermantasyon tekniği ile Bacillus circulans ATCC 4516'dan ekstrasellüler $\beta$-galaktosidaz üretimi. KSU J Agric Nat, 22(3), 480-486. doi:10.18016/KSUTARIMDOGA.VI.503414

Shah, N.P. and Otieno, D.O. 2007. Endogenous $\beta$-glucosidase and $\beta$-galactosidase activities from selected probiotic microorganisms and their role in isoflavone biotransformation in soymilk. J Appl Microbiol, 103 (4), 910-917. doi: 10.1111/j.13652672.2007.03438.x

Son, S.H., Jeon, H.L., Jeon, E.B., Lee, N.K., Park, Y.S., Kang, D.K., Paik, H.D. 2017. Potential probiotic Lactobacillus plantarum Ln4 from kimchi: Evaluation of $\beta$-galactosidase and antioxidant activities. LWT-Food Sci Technol, 85, 181-186. doi: 10.1016/j.lwt.2017.07.018

Ustok, F.I., Tari, C., Harsa, S. 2010. Biochemical and thermal properties of $\beta$-galactosidase enzymes produced by artisanal yoghurt cultures. Food Chem, 119, 1114-1120. doi: 10.1016/j.foodchem.2009.08.022

Venkateswarulu, T.C., Prabhakar, K.V., Kumar, R.B. 2017. Optimization of nutritional components of medium by response surface methodology for enhanced production of lactase. 3 Biotech, 7, 202. doi: 10.1007/s13205-017-0805 
Wheatley, R.W., Lo, S., Jancewicz, L.J., Dugdale, M.L., Huber, R.E. 2013. Structural explanation for allolactose (lac operon inducer) synthesis by lacz-galactosidase and the evolutionary relationship between allolactose synthesis and the lac repressor. J Biol Chem, 288, 12993-13005. doi: 10.1007/s13205-017-0805-7

Xin, Y., Guo, T., Zhang, Y., Wu, J., Kong, J. 2019. A new $\beta$-galactosidase extracted from the infant feces with high hydrolytic and transgalactosylation activity. Appl Microbiol Biotechnol, 103(20), 8439-8448. https://doi.org/10.1007/s00253-019-10092-x

Yu, P., Li, N., Geng, M., Liu, Z., Liu X., Zhang, H., Zhao, J., Zhang, H., Chen W. 2020. Lactose utilization of Streptococcus thermophilus and correlations with $\beta$-galactosidase and urease. $J$
Dairy Sci, $103 \quad$ (1), 166-171. https://doi.org/10.3168/jds.2019-17009

Zhang, H., Li, W, Rui, X., Sun, X., Dong, M. 2013. Lactobacillus plantarum 70810 from Chinese paocai as a potential source of $\beta$-galactosidase for prebiotic galactooligosaccharides synthesis. Eur Food Res Technol, 236, 817-826. doi: 10.1007/s00217-013-1938-5

Zhang, W., Wang, C., Huang, C.Y., Yu, Q., Liu, H.C., Zhang, C.W., Pei, X.F., Xu, X., Wang, G.Q. 2012. Analysis of $\beta$-galactosidase production and their genes of two strains of Lactobacillus bulgaricus. Biotechnol Lett, 34 (6), 1067-1071. doi: 10.1007/s10529-012-0870-2 